\title{
Organisational Identification of Academic Staff and its Relationship to the Third Stream
}

\author{
Trevor A Brown
}

Business Development Manager Manchester Metropolitan University Cheshire, College House, Crewe Campus, Crewe Green Road, Crewe, Cheshire, CW1 5DU t.a.brown@mmu.ac.uk

\begin{abstract}
This preliminary study seeks to add to the growing literature on knowledge transfer and the entrepreneurial university by establishing the identity of academic staff and their perception of how this identity is reflected by their organisation, referred to organisational identity. In addition, the study aims to establish the academics understanding of commonly utilised terms such as Academic Enterprise and Third Stream. These terms are frequently used in strategic and management documentation driving and defining the new entrepreneurial activities of a university. This understanding is explored in relation to the level of organisational identification, in order to develop a perspective of a universities third stream strategies from an Academic Identity standpoint. The study is undertaken within one faculty of Manchester Metropolitan University.

The findings show that organisational members understanding of the third stream is founded within the context of the Academics Identity. Core identity factors within Teaching and Research such as, Academic Autonomy, the Discipline, Obligations to the Learner and the Community are also reflected in the academic's definitions of Academic Enterprise and Third Stream.

The organisational members undertake third stream and knowledge transfer activities, due to their inherent links to their core identity, not due to managerial drivers such as income generation. The third stream and knowledge transfer activities are found to be a core part of their academic identity, not a separate adjunct. The level of organisational identity is found to be low and where Third Stream activities exist they occur in spite of, or regardless of the organisation, they occur because of the nature of Academic Identity. There seems little evidence (given the limited scope of this small evaluative and qualitative study) that organisational members are engaging with TS as a result of the Organisations Strategy.
\end{abstract}




\section{Introduction}

A university is a organisation where academics study, research and teach students. The archetypal "academic" has an image and identity that is as clear as a doctor or fireman. However the nature of a university is changing, the university is now required to seek out new relationships with businesses and non traditional "customers", delivering learning and knowledge in new ways, frequently driven by commercial demands. University senior management teams are motivated by government and funding to meet these demands and steer the university towards these new goals. These new areas of activity are often referred to as the "Third Stream" TS (teaching and research being streams 1 and 2). The new mission, strategies and definitions of third stream initiatives form a changing organisational identity for a university which may challenge widely held notions of a universities identity by its member staff, the academics. Dutton et. al. (1994, p1) state; "Strong organisational identification may translate into desirable outcomes". If the university wants its members (the academics) to embrace the changing mission of a university and undertake actions in support of the new mission, university managers must understand the organisational members (the academics) relationship to the new identity and aim to engender a strong organisational identity. Unpicking the academics definitions of aspects such as TS and academic identity, and how individuals engage with, relate to, or define the new organisations identity being formed out of the changing nature of universities, could give indications as to what constitutes their organisational identity and the level of "identity dissonance" (Elsbach et. al., 1996, p1). A clear understanding of this dissonance would support university managers understanding of members engagement with the strategy and mission in support of TS. Once modelled this then could lead to recommended actions which generate "intraorganisational cooperation or citizenship behaviours" (Dutton et. al., 1994), thereby supporting the strategic direction of the organisation.

Via the literature review the study will research and then establish a set of factors of academic identity and utilise these to investigate the organisational members identity and their perceptions of how this identity is valued by the organisation, described as organisational identity. A set of factors for third stream will be developed and utilised to establish the academics understanding of third stream and its importance to them. This will establish a level of organisational identity and how third stream impacts upon and relates to this identity.

\section{Literature review}

\section{Organisational Identification and Strategy}

Current thinking, according to Rughase (2006), is that strategic management practice focuses on logical aspects and gives examples such as the favoured economic resolution and states that other aspects such as values and emotions of organisational members are dismissed. Leibl (2001) and Mezia et. al. (2001), (cited in Elsback, 1996) back these notions up commenting that "Strategies often fail as they do not join the prevalent concepts and desires of organisational members". An- 
drews (1987, p. 19) sets an early baseline in this thinking, arguing that the values, ideals and aspirations of individuals influence purpose and need to be brought into strategic decision making and that problems within strategy implementation were because, during strategy formulation, the members past thinking, personal values, cultural loyalties, rules and restraints which formed beliefs about their organisation, where not incorporated. Dutton et. al. (1994) introduces a further aspect of identity with strategy describing how the individual organisational member will interpret the various strategic issues, this interpretation will then influence which strategies are noticed and which are not.

Dutton et. al. (1994) models an individual's identity and self concept as a relationship to the organisations identity and how this "organisational identity" can in turn shape an individual's identity. It specifically focuses on the individual's image of their organisation. The degree to which the members concept of their personal identity is perceived (by the member) as having the same attributes as the organisation is described by Dutton et. al. (1994) as "organisational identification" The author produces a strong argument that members of organisations will change their behaviours by thinking differently about their organisation. It is argued that a positive organisational identification may convert into desired outcomes, examples include; intraorganisational cooperation or citizenship behaviours. More recent studies have supported this argument and found interactions between organisational identification, motivation and well-being. (Wegge et. al. 2006). The process of identification is described by Ashforth et. al. (1989) as one of selfcategorisation formed through ritual, ceremony and stories which support the communication of the identity to members. Negative relationships between members and the organisational image are also found to produce negative business outcomes, as was found by Dutton et. al. (1994) with the Port Authority New York and Exon executives. This can result in undesirable outcomes such as constrained positive actions towards responsibilities or tasks. An aspect not explored, but which may occur, is a null response, the organisational member may not experience sufficiently strong or negative organisational identity to produce any response of significance.

Mael and Ashforth (1992) point out that a professional and or occupational identity are not automatically specific to the members organisation and that values within a profession may conflict with those of the employing organisation. Here Mael and Ashforth (1992) separates the identity a member has with the organisation (I work for Manchester Metropolitan University) from the identity the member has with a profession (I am an academic). This is referred to as "Professional and occupational identity", the member defines him/herself in terms of what they do rather than who they do it for. It is argued (Vanmaanen and Barley, 1984) that members embrace the archetypal character attributed to individuals within that work.

\section{A "Conceptual Framework" for Organisational Identity}

Following Yin (1994) (cited in Saunders et. al., 1997 p, 348), the study will make use of existing theory to devise a framework within which to conduct the research. The model derived from the literature review is expressed here as a "Conceptual Framework" (Robson,1993 p 63) and is shown in Figure 1. 
Fig.1. Organisational Identification (Modified with academic titles, Dutton et. al., 1994)

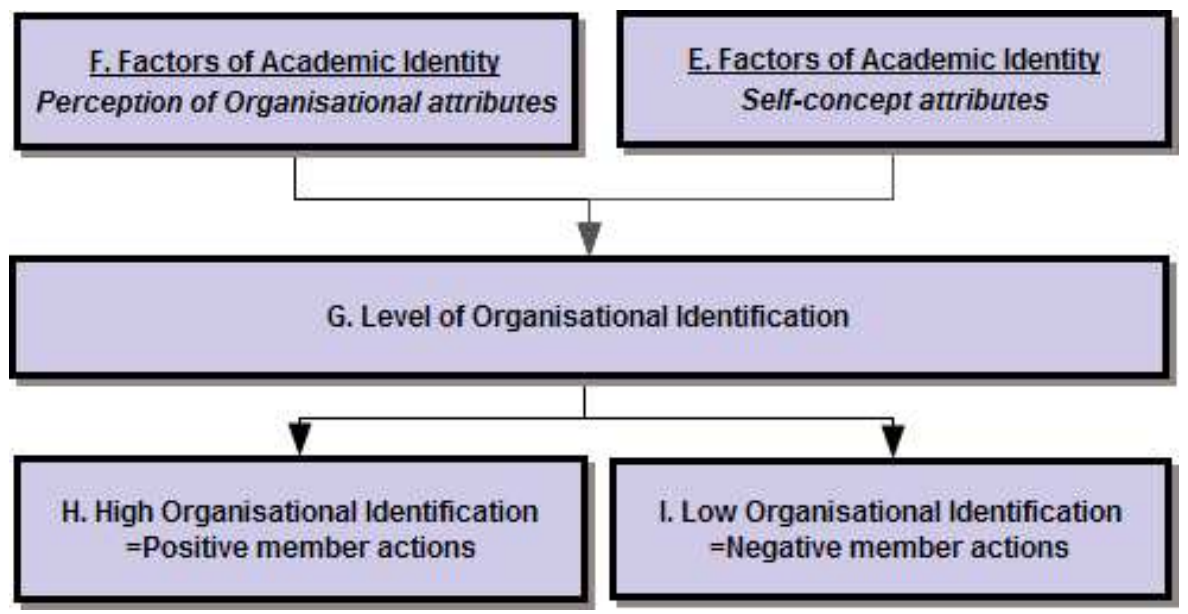

The original model of member identification developed by Dutton et. al. (1994) can be demonstrated in Figure 1. Please note the researcher has adapted the model to utilise academic member titles, however the general model remains, i.e. that the members perception of self (E) interacts with members perception of the organisation $(F)$, this results in a level of organisational identity $(\mathrm{G})$. Dutton et. al. (1994) establishes that a High Organisational Identification will equate to positive member actions in support of the organisation $(\mathrm{H})$ and that a low Organisational Identification will result in negative member actions in support of the organisation (I). Please note; the arrows denote a causal relationship and influence in the direction of the arrow.

\section{Third stream within the literature and the Entrepreneurial University}

This new strategic development area for universities can often be referred to as, or encapsulated within the term "Third Stream" (TS). Academic studies on university TS activity is a relatively new field with literature remaining "rather fragmented" (Rothaermel et. al. 2007, p. 1). Rothaermel et. al. (2007) conducted a review of the TS literature and found that reference to academics outside of technology transfer roles are distinctly absent; the majority of papers study professional entrepreneurial staff within the university structure, not academics operating in the mainstream (teaching and research).

This focus on technology transfer roles highlights the entrepreneurial perspective found in the majority of literature on TS. A leading study on the entrepreneurial university undertaken within the Triple Helix University-Government-Industry model (Etzkowitz, 2008) develops the notion of industry, government and university interlinked for the purpose of innovation and entrepreneurship. The focus is on the entrepreneurial expressed as the development of the quazi firm, technology transfer offices and research groups. In regard to the individual academic Etzko- 
witz (2008) describes the ideal for supporting the Triple Helix as an academic with a foot in both camps, one in academe and the other in industry and firm (company) formation within or linked to universities. The participating individual is a distinct entrepreneurial academic and separate from the mainstream operations of the university. This review of an entrepreneurial university is developed from an entrepreneurial academic perspective, either developing new firms, organisations and patents or developing staff to be more entrepreneurial. This approach to TS development is shown to be effective and is demonstrated as the basis of developments at MIT and Stanford but does not satisfactorily address his findings that: "Many academics believe that a university best fulfils its mission by limiting itself to education and research" (Etzkowitz, 2008, p. 4) . As demonstrated with Etzkowitz (2008), the majority of work on TS relies on a definition of TS from an academic entrepreneur perspective. A definition of TS is unclear, yet TS within an entrepreneurial framework is placed within university strategic aims, mission and vision e.g "An enterprising organisation with enterprising staff and students;" (MMU 2008) with income targets, within the strategy, defining engagement in entrepreneurial and financial terms. The scope of TS activities is limited, definitions of TS falling almost exclusively within entrepreneurial and commercial/financial activities.

\section{Methodological approach}

The research consisted of a small deductive research project, interviewing seven Academics, within an example organisation (MMU Cheshire Faculty), to understand the context and processes within the organisation (Morris and Wood, 1991). The main driver of the study is to explore organisational identification and the organisational members responses to impacts on their identity, derived from Dutton et. al. (1994), in particular the emergence of TS and its impact on members (the academics) identity. This is approached via a qualitative interpretation of a methodology constructed for a study of alumni (Mael and Ashforth, 1992). The original model incorporates generic measures of organisational identity but requires adapting to the specific organisational context. This study will develop new relevant antecedents via the literature review, which will establish a baseline of significant antecedents expressed here as Possible Factors of Organisational Identification / Academic Identification.

\section{Correlates of academic identity}

For this study new specific Correlates of Organisational Identification are required which will apply to and contextualise the model of organisational identification, for clarity I will refer to these as "Factors of Identity". Henkel (2005) undertakes a study of academic identity within policy changes, utilising "communitarian moral philosophy and symbolic interactionism" as the basis for a review of academic identity. The author unpicks aspects of academic identity prior to the changing environment (of academia) and then discusses the change factors impacting on academics. I have utilised the Henkel (2005) paper to establish the key Possible Factors for academic identity as follows; 


\section{Possible Key Factors of Identity}

- Academic as a living tradition, the history and role

- Academic autonomy- (pattern working life / quality of life)

- Academic control of teaching and research

- Academic freedom (research agenda and priorities)

- Bounded academic space, The strong

- Classification and boundaries between groups and disciplines, The strength of

- Community of scholars, The defining

- Community other, The defining

- Department, The

- Disciplinary culture

- Discipline, The

- Epistemology, The

- Institution, The

- Integration into the community, The level of

- Managerial culture, The

- Multiple and contradictory identities (avoiding fixation on a single identity)

- Narrative account of self and changing of identity over time, The

- Obligations, fulfilment and respect of the community, The

- Power of the group/community, The

- Status in the nation "definers, producers, transmitters and arbiters of advanced knowledge"

- Unit, The

Values and beliefs of the community, The

Although Henkel (2005) outlines these differing parts of the academic identity, this work is undertaken within a presumption that the academic identity is entirely formed within academic related activity or employment. The academic will have a broader range of inputs to their identity than implied by their current role.

\section{Academic Enterprise and Third Stream}

According to Molas-Gallart et. al. (2002)

"There are no magic bullets in indicators of Third Stream ac-
tivities. A variety of indicators need to be collected. Each of
them will, by itself, be incomplete and its interpretation will
be open to questioning. Yet when taken together, the result can
be a powerful measurement system." This is supported by Alice Frost Head
of Business and Community Policy at HEFCE (2008). "What I have found in
discussing different terminologies, is that when any individual
or organisation tries to define terms, they become reductionist
of the agenda. And while third stream funding has been around
for many years now, one person's or HEI's definition of the
terms can be very far from another's". In reference to the above 2 views 
the researcher is defining the case study's interpretation of TS by the organisations own measures. These measures will to some extent, represent the strategic direction and drivers for the university. The researcher has utilised the case study organisations internal HEFCE reporting document titled "HEIF 4 Pro Forma". This is a document used to capture TS in faculties for central reporting. This form is supplemented by the Academic Enterprise Strategic plan developed in 2007 and the MMU Cheshire Strategic Plan 2007-2008. Evaluation of these documents revel the following;

\section{Factors of Academic Enterprise and Third Stream}

- $\quad$ Academic Enrichment

- $\quad$ Collaboration development

- $\quad$ Community Engagement

- $\quad$ Conferences

- Consultancy

- $\quad$ Contract research (Business funded or Applied research)

- Curriculum Development Mainstreaming of innovative products

- $\quad$ Development of Knowledge

- $\quad$ Employer led accredited courses

- $\quad$ Engagement with business

- $\quad$ Engagement with regional forums

- $\quad$ Facilities and equipment services

- Formal understanding of business need in region.

- Formal understanding of community need in region

- $\quad$ Funded Projects

- $\quad$ "High Interest" activity development

- Income generation/ commercial income

- Increase graduate recruitment

- $\quad$ Increased Student Numbers

- International links with Universities and HE Colleges

- $\quad$ IP Intellectual Property income

- KTPs

- $\quad$ Outreach and networking

- $\quad$ Partnership opportunities

- Partnerships Brokering relationships/networking:

- $\quad$ Partnerships business assists

- $\quad$ Partnerships joint funding applications.

- $\quad$ Professional Body Links

- $\quad$ Raised awareness amongst businesses.

- Reputation for Knowledge

- $\quad$ Short courses (non accredited)

- $\quad$ Student enterprise

- $\quad$ Raised profile of staff within the business sector.

- Recognition as a Knowledge Centre 
- $\quad$ Staff development

- $\quad$ Student enterprise training

- $\quad$ Student Social Enterprise schemes improving employability.

- Utilisation of a wider staff skills base

These forms and the definitions of TS, are the case study organisations main methods for driving and capturing TS activities and as such represent the organisations summary or definition of TS. The categorisation and member interpretation of TS activities will directly influence the member's perception of the organisation and impact on their self concept. This can be illustrated with a revision of figure 1, adding the Third Stream Change Factors to the Organisational Identification model. The original model (figure 1) has been modified here (figure 2) to evaluate the impact of a change factor (A), the Third Stream, on the member academic's Organisational Identity $(\mathrm{G})$, the arrows within the model representing causal links. The level of impact (C and D) of Third Stream will be determined by the member academics interpretation of Third Stream (B). This interpretation is influenced by how the organisation has categorised or implemented this change (A). The extent to which the impacts (C and D) interact with the members organisational identity $(\mathrm{G})$ may then have positive or negative effect on member actions ( $\mathrm{H}$ and $\mathrm{I}$ ) in support (or not) of the perceived Organisational Identity $(\mathrm{G})$. The researcher is particularly interested in whether these member actions ( $\mathrm{H}$ and $\mathrm{I})$ will be actions defined within the organisations Third Stream definitions (A) or not. This may reveal whether; 1 . The TS initiatives have become characteristics of the organisation and 2. They have become a part of their self concept. (Dutton et. al., 1994)

Fig. 2 Organisational Identification with the Third Stream Change Factor. (Conceptual Schema)

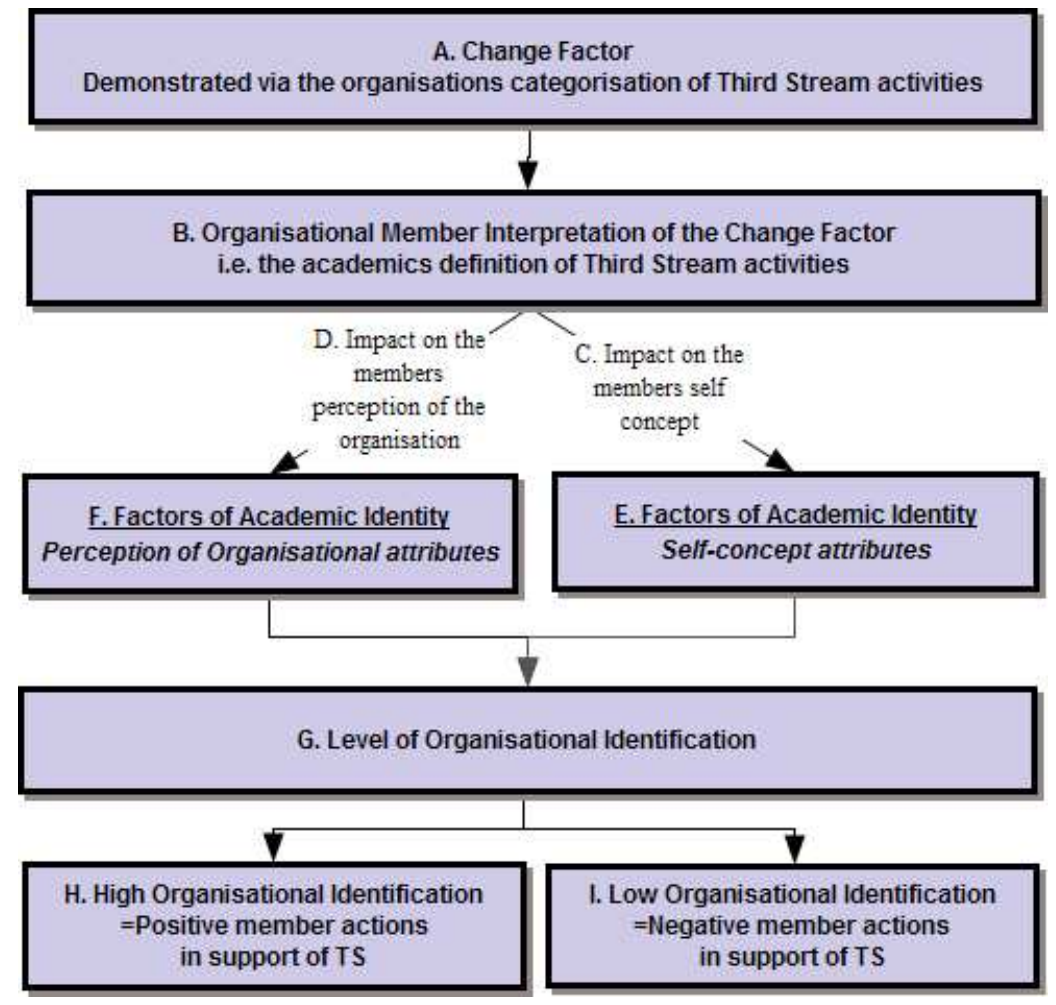




\section{Interview Schedule}

Seven academics where selected for the study. Individual member data was be established, including; Length of service in MMU, Length of service as an academic, Role, Title, Subject area, Prior career, Age and an approximation of the time spent on Teaching, Research, Administration and Other activities was established. An open semi-structured interview on Academic Identity / Organisational Identity followed, utilising the factors for academic identity, issued to the interviewee as cards to prioritise in response to a set of questions.

Academic Enterprise and Third Stream was explored using open semi-structured interview about the individual's definition and how they perceive it. Utilising key factors for Third Stream and Academic Enterprise (separately) issued to the interviewee as cards to prioritise in response to a set of questions.

Note; please contact the author for details on data sets, quotes and processes.

\section{Findings}

\section{Qualitative Level of Organisational Identification}

The combination of interviews and chosen factors give a qualitative and initial indication of the level of Organisational Identification perceived by the organisational members, the interviewees.

Managerial Culture vs Academic Autonomy/Freedom/Control, (Administration)

The joint highest priority of all negative factors of OI was that of a Managerial Culture, and this is viewed as a priority for the organisation. Local management was less of an issue, but imposed decisions, from higher in the institution, are the main concern. A key enactment of this Managerial Culture is found within administrative duties. The level of these activities encountered by the organisational member is in direct conflict with the notion of Academic Autonomy/Freedom/Control, the highest positive factor of OI. Although the organisation is viewed as supporting Academic Autonomy/Freedom/Control this is felt to be a surface level of support and the administrative burden imposed by the Organisations Managerial Culture is perceived as impacting on this freedom. Further aspects of the Organisations Managerial Culture appear to impinge on developments wanted by the Organisation and there is no perceived management or operational support for these organisational goals. The Strength of Differentiation between the disciplines was also viewed as a management issue not valued by the academic members, resulting in further perceptions of the organisations management not supporting the members, when cross faculty or department action are required.

Institutional Hierarchy

In most cases the levels of Institutional hierarchy appear to be directly related to the level of IO. There does appear to be OI with the individual unit, a significant level OI with the Department, less but some with the Faculty and little or non with 
the Institution. However this was not the case with one interviewee with the shortest length of service, 1.3 years, who did state a positive level of OI with the institution.

The Henkel (2005) derived factors of identity where found to be lacking in 2 areas. Comments from interviewees led to 2 new factors emerging during the interviews;

1. Obligations to the Learner and 2. The External Community.

Obligations to the Learner

This factor is joint highest value to the organisational members. Overall the respondents felt that the institution does support a value of Obligations to the Learner, however the actions and disappointments concerned with operations and administration, counter this, leading to the interviewees feeling that it is not valued in reality.

Others

Community is a high positive factor of member's identity but believed to be undervalued by the institution. The level of OI within the Disciplinary Culture (Academic not Managerial) is low, with a feeling that student numbers drive the organisation not the quality of the academic disciplines.

A Summary of the Qualitative level of Organisational Identity

The combination of factors of Academic Identity and an analysis of the interviews leads to an evaluation of the "perceived organisational identity" (Dutton et al. 1994, p.1). From the information gathered it is clear that the small evaluative sample of Organisational Members interviewed, is experiencing a Low Level of Organisational Identification with the University. This can also referred to as "organisational dissonance" (Elsbach and Kramer 1996). There is a an emergent possibility that this relationship is time dependent, with the newest member of staff having the most positive OI with the institution, further study would be required to evaluate this. This does seem to contradict the literature as Mael and Ashforth (1992) found that the length of time a person is associated with an organisation has a positive impact on their level of organisational identity.

The academics definition of Third Stream and Academic Enterprise

The organisational member definitions and understanding of what AE and TS are, is varied and contradictory. Some of the members feel it is the same thing, others view it as entirely different and for those that view TS and AE as the same, they have very different interpretations of this. Money features highly within the interviews and there is a mixed view as to how this defines TS and AE. Overall there is an understanding that AE or TS (dependant on the individual) will include some aspect of income generation, however all the interviewees would tend to contextualise the money aspect, defining it as clean or "dirty" money, separating out relationships between community and business and highlighting its links to research and teaching. It is notable that only one organisational member stated that AE was defined by where the funding originated, i.e. not HEFCE funding, however this 
was stated for AE not TS. From the organisations standpoint this is the TS definition. For those members who embed AE within Teaching and Research the relationship to money is viewed as a negative attribute. Overall the money aspect of the TS and AE definitions is a part of the members definitions, which to a greater or lesser extent was recognised. However during discussions on money, each member preferred to define TS and AE by other characteristics which complemented, or was an intrinsic part of, their teaching, research, knowledge exchange ("ideas out"), community obligations and their career choice in becoming an academic.

A further observation regarding this contextualisation is reflected within the subject areas. Those members who rate $\mathrm{AE}$ as a high importance are within a Business and Management Department and those with the low importance are academics within Literature subject area, obligations to the community and knowledge exchange being drivers for this differentiation.

Although TS activities are measured by the organisation as separate activities, this is not necessarily the operational experience of the members. The "Other Activities" question raised the definition of how the member perceives AE and TS. Overall AE and TS are perceived as an embedded part of the member's core roles of teaching and research (of which administration, in this context, is a part). This resulted in many of the members being unable to separate the four activities (Research, Teaching, Administration and Other Activities) into distinct sections, as the researcher had envisaged.

Summary of the definition of TS and AE

These results combined with the AE and TS factor choices, gives an understanding of the members definitions of AE and TS being formed almost entirely from an individual and academic perspective. Teaching, research, knowledge exchange ("ideas out"), community/learner obligations and their career choice in becoming an academic are the main defining drivers for definitions of AE and TS. Aspects of income generation are viewed as organisational drivers for TS and AE and its importance in defining TS and AE is secondary to individual and academic drivers.

\section{Conclusion}

The effect of the members AE and TS definitions on the level of Organisational Identity

The organisational members understanding of AE and TS is founded within the context of the factors of Academic Identity detailed earlier. The core activities of Teaching and Research enacted through Academic Autonomy, the Discipline, Obligations to the Learner and the Community are reflected in the definitions of TS and AE. Although the factors for AE and TS where all recognised by the organisational members, they are perceived within and/or as a compliment to their core identity. The organisation has developed a set of measures (the factors) formed from funding demands and the changing nature of universities, not based on this 
core identity. This results in a set of factors and definitions which are the same yet with perspectives, priorities and drivers for engagement which are quite different. The organisational members enact TS and AE activities because of the links to their core identity, not for income generation. As the (AE and TS) definitions are based on the notion of Academic Identity then this change factor is subsumed into the definition of the Academic Identity. TS and AE are a part of the Academics Identity and therefore the qualitative evaluation of members OI remains unchanged. However the financial aspects of AE and TS are negatively viewed by the organisational members and this association may result in an increased level of Negative Organisational Identification as these financial aspects are highlighted by the organisation.

\section{Does a Low Organisational Identification = Negative member actions in sup- port of Third Stream? (please refer to figure 1)}

The model developed in Figure 3 anticipates that a low level of OI will result in negative member actions. Given the limited scope of this research a tentative initial finding would be that this part of the model stands correct. The impact of the negative OI is either inconsequential or results in negative actions. Where TS activities exist they occur in spite of, or regardless of the organisation, they occur because of the nature of Academic Identity. Where they do not occur, associations with managerial culture (the key negative organisational factor) and its impact on academic freedom, appear as the main aspects of the "organisational dissonance" (Elsbach and Kramer 1996). As there is no data to support a "High Organisational Identification =Positive member actions in support of TS" (please refer to figure 3 , section $\mathrm{H}$ ). No assumptions can be made as to the validity of the section of the model.

\section{Engagement with the TS Strategy}

As the definition and value of TS and AE has been found to be an intrinsic part of; the organisational members identity, their Academic Identity and interpreted through this identity, there seems little evidence (given the limited scope of this small evaluative and qualitative study) that organisational members are engaging with TS as a result of the Organisations Strategy. There is some pragmatism from one member expressing a view that if her job depended upon it (TS) her priorities would change, but this was a single comment. Priorities for all members where focussed on teaching followed by research and the TS activities that emerge, are the result of their complementing and supporting the members core identity and values, not because of any strategic initiatives. In one case the interviewee believed that institutional issues such as the managerial culture, worked against the freedom required to deliver TS initiatives and progress towards organisational goals and strategy was hampered.

\section{Organisational Identification and Strategy}

In answer to the research objective "To investigate to what degree does strong organisational identification in mainstream staff, result in significant engagement with the TS strategy." There is no strong OI, a weak or negative OI exists within 
the selected members. This negative OI or "organisational dissonance" (Elsbach and Kramer 1996), as a minimum, may have no effect on their engagement with the TS, as the engagement is dependant on the Academic Identity not on Organisational Identity. However this negative OI may also impact on engagement with TS as aspects of the organisations identity, linked to the management of TS (e.g. income generation), are in conflict with the organisational members identity, and may result in a negative impact in engagement with the organisations TS strategy. One unexpected observation is the shock experienced by the members at the number of AE/TS factors issued during the interview. As is stated within the Enquiry Design section, the selection of these 38 factors was based on various organisational documentation, the individual factors come directly from these documents. It was clear that the range of $\mathrm{AE}$ and $\mathrm{TS}$ activities had not been presented to the members previously. This raises questions as to how engaged the organisational members are in the strategy making process and the how engaged they are with strategies in operation. Arguably the range and diversity of the factors for TS would be more familiar to the organisational members if a greater degree of interaction had taken place.

Fig 3 A model of Academic organisational identification in relation to change and actions

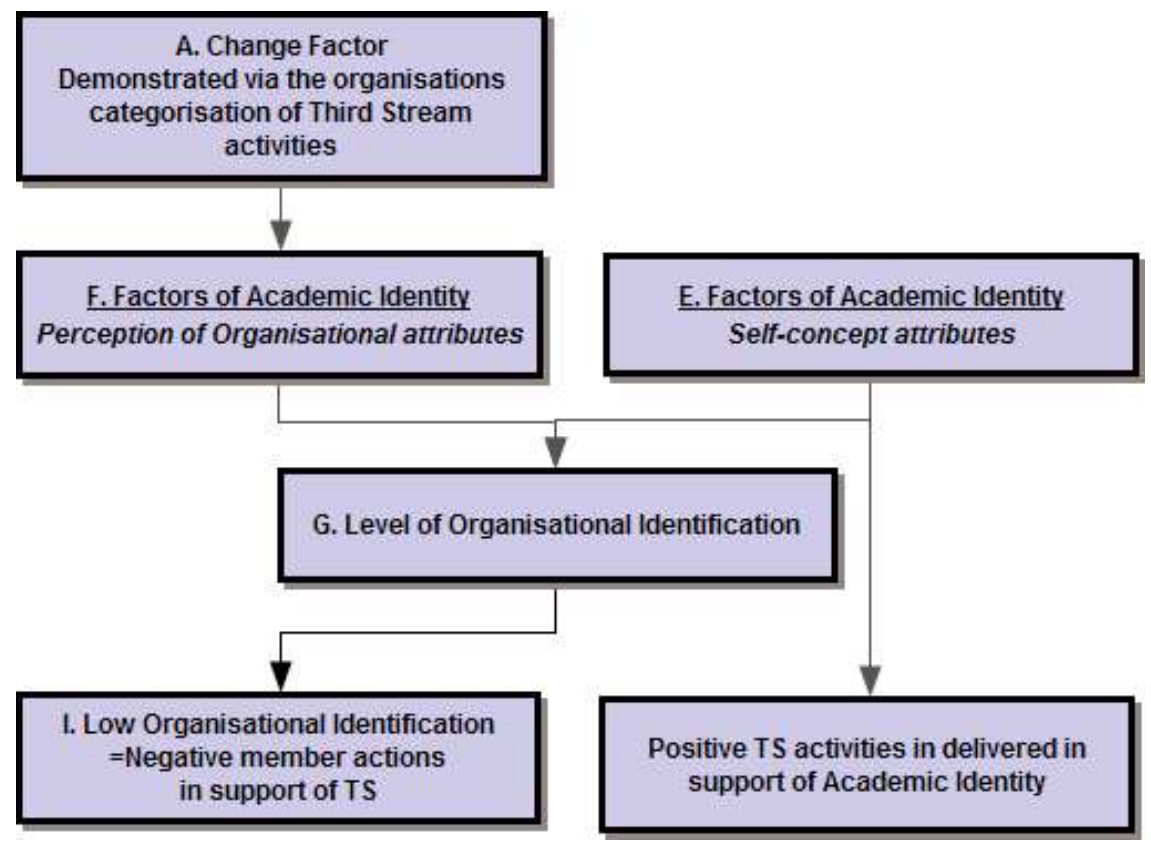

Figure 3 proposes an adapted summary model of Academic OI in relation to change and actions, observed in this study. Factors of self concept or Academic Identity are the drivers for actions in support of TS, the level of OI is negative and equates to negative actions in regard to TS. 


\section{Changing Mission}

The literature review established that a changing mission for universities was a key element of the development of TS activities. This study gives some indication that this issue of the changing mission seems less prevalent in the development of TS. The issue for individual academics is how the changing mission manifests within managerial culture. TS appears to be an embedded core value that exists and need not be grafted on, academics need not change their core identity to accommodate these demands. It would appear that it is the management of the engagement of academics in the strategy and processes for TS that require reevaluation. These strategies currently formed into income targets, are the core strategic measures operated by the organisation and it is these that need to be contextualised against individual academics drive and obligations to deliver TS activities in support and in compliment to their teaching and research.

\section{Entrepreneurial academic and mainstream academic}

The researchers first thoughts on the separation between an entrepreneurial academic and mainstream academic, formed from authors such as Etzkowitz (2008). Etzkowitz (2008) recognises that "Many academics believe that a university best fulfils its mission by limiting itself to education and research" (Etzkowitz, 2008, p. 4). The assumption is that this would not be entrepreneurial and by his definitions not include TS. The findings for mainstream academics show that TS is embedded within the teaching and research and is at the core of academics identity, so the proposed opposition between a mainstream academic and an entrepreneurial academic is not as clear as imagined.

\section{Strategic and research recommendations}

1. Expansion of the study

A further study of a case study organisation that links its strategy to academic identity drivers would be useful in developing these ideas further. This would need to longitudinal and considerably broader in the numbers of academics studied.

\section{Broader innovation and policy research.}

Further studies could evaluate the relevance of organisational identity with business/university relationships and the development of TS activities, in relation to Furman et. al. (2002) and Etzkowitz (2008). Exploring how organisational identity supports the strong relationships required for TS.

\section{Strategic recommendations}

A final conclusion of this study is to make an early presumption on the approach managers could take to develop TS activity within the university. The recommendation would be to utilise the factors for academic identity as a key driver of engagement, thereby developing an engagement strategy that complements and is formed from the embedded identity demonstrated by the academics. Engagement of the academic teams in TS strategy development and realigning the strategic goals to be based on academic drivers rather than monetary drivers would support engagement and increase activity, the final outcome being increased TS activity. 
Fig.4 Strategic recommendations

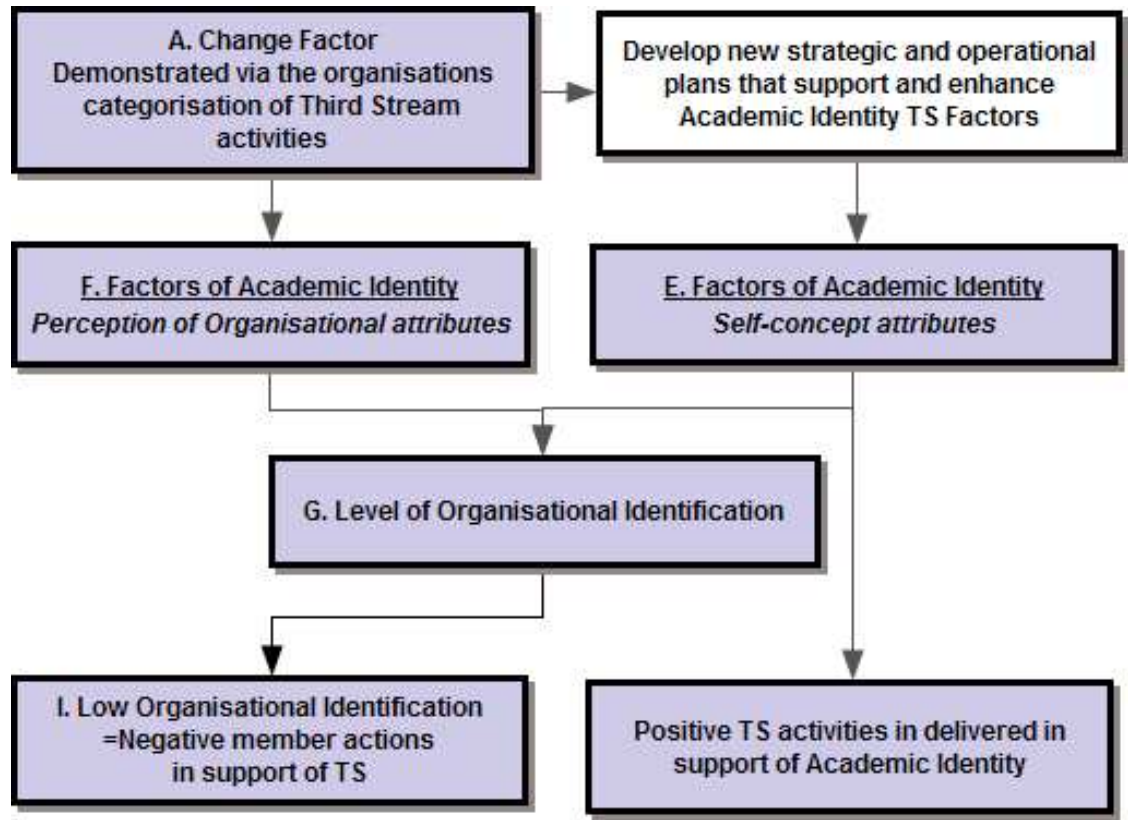

In speculating an approach for this strategic recommendation university managers could undertake a subject group based approach to understanding the academics perspectives, priorities and drivers. Types of TS activity could be matched to these groups and the complementary benefits of these TS activities highlighted to the group, on their terms. This will involve a redefinition of some types of TS activity and work to remove the separate status TS activity has from the core roles of teaching and research. An example of this could be proposed with KTP project development. Currently these KTPs are "sold" internally to academic staff as a way of generating income and complementing the TS strategy. A new approach would be to emphasise aspects of the project which complement the individuals "Academic Identity self concept attributes".

For example this could include an emphasis on the;

- Academic freedom intrinsic within a KTP (time, budget and subject area).

- Benefits to community organisations (improvements to services, cost savings).

- Benefits to the learners from up to date and direct research through KTP.

- KTP as a different teaching environment (an organisation rather than a class).

- Demonstrated examples of similar academic "types" working on projects which support these" Academic Identity self concept attributes".

\section{Boundaries and limitations}

A limitation of my research is my interest with a type of worker within the organisation, who I refer to as the "mainstream academic". An academic may have a significantly large teaching load during the sample, or opportunity to engage has 
not arisen. The current job descriptions of staff do not explicitly include TS as a duty, so although specified strategically, locally the academic may not see this as their role or task, the academic may have high organisational identity but not engage in TS, whichever definition is utilised. Assumptions where also made that the academic is aware of the universities third stream strategy.. Mael and Ashforth (1992) find limitations in the proposed methodology as they state that the "causal sequence from antecedents to identification to consequences" is untestable and recommend a "within-subjects longitudinal approach to capture the dynamics of identification over time". The study is cross-sectional and this will need to be accounted for in the findings. The researcher, myself, is working within the case study faculty as a Business Development Manager, although this has led to my interest in the research subject, I am a key staff member in TS development directly reporting to the Dean. The risk of unseen researcher bias due to this position is high; objectivity and the need to remain an external observer are problematic. There is also the risk of respondents adapting answers to meet expectations associated with my role, and my links to senior management, this link could also be used to send a message to senior management. The sample group of "mainstream" academics selected from a random group of teaching academics, is subject to differing operations and cultures within each department. For example the core delivery hours for teaching vary considerably, the financial reward system is interpreted differently and departmental cultures differ. The chosen sample size of 7 has limitations. Across 2 departments this would averages out at 3-4 Academics for each department. With the variations between departments this may dilute the sample.

2 of the interviewees commented on the number of factors for TS, presented as cards in the interviews. The number of factors reflects the range of factors visible in documentation used within and forming the TS strategies for the university. As such this is representative of the scope of activities covered by the TS definition. Comments are also found in the subtle differentiations between factors for TS, interviewees commenting that some of the factors are too close in their meaning. Although the researcher has removed distinct doubles in the development of the factors, this level of sophistication is required to establish the interviewee's real understanding of each factor.

\section{Bibliography}

Andrews, K. R. (1987). The Concept of Corporate Strategy). USA: Irwin.

Ashforth, B. E., \& Mael, F. (1989). Social identity theory and the organization. Academy of Management Review, 14(1), 20-39.

Dutton, J. E., Dukerich, J. M., \& Harquail, C. V. (1994). Organizational images and member identification. Administrative Science Quarterly, 39(2), 239-263.

Eisenhardt, K. M. (1989). Agency theory - an assessment and review. Academy of Management Review, 14(1), 57-74.

Elsbach, K. D., \& Kramer, R. M. (1996). Members' responses to organizational identity threats: Encountering and countering the Business Week rankings. Administrative Science Quarterly, 41(3), 442-476. 
Etzkowitz, H. (2008). The Triple Helix University-Industry-Government Innovation in Action. New York: Routledge.

Frost, A. (2008). Third stream, taxonomy and the value of ambiguity?, Conversations the IKT $B \log$ ). London.

Furman, J. L., Porter, M. E., \& Stern, S. (2002). The determinants of national innovative capacity. Research Policy, 31(6), 899-933.

Gagliardi, P. (1986). The Creation and Change of Organizational Cultures - A Conceptual Framework. Organization Studies, 7(2), 117-134.

Gioia, D. A., Schultz, M., \& Corley, K. G. (2000). Organizational identity, image, and adaptive instability. Academy of Management Review, 25(1), 63-81.

Gioia, D. A., \& Thomas, J. B. (1996). Identity, image, and issue interpretation: Sensemaking during strategic change in academia. Administrative Science Quarterly, 41(3), 370-403.

Henkel, M. (2005). Academic identity and autonomy in a changing policy environment. Higher Education, 49(1-2), 155-176.

Johnson, J., Scholes, K., \& Whittington, R. (2006). Exploring Corporate Strategy ( $7^{\text {th }}$ ed ed.): Essex: Pearson Education Limited.

Mael, F., \& Ashforth, B. E. (1992). Alumni and their alma-mater - A Partial test of the reformatted model of organizational identification. Journal of Organizational Behavior, 13(2), 103-123.

Markman, G. (2004). Entrepreneurship from the Ivory Tower: Do Incentive Systems Matter? Journal of Technology Transfer, 29, 353-364.

Martinelli, A., Meyer, M., \& von Tunzelmann, N. (2008). Becoming an entrepreneurial university? A case study of knowledge exchange relationships and faculty attitudes in a mediumsized, research-oriented university. Journal of Technology Transfer, 33(3), 259-283.

Mintzberg, H. (1990). The Design School - Reconsidering the basic premises of strategic management. Strategic Management Journal, 11(3), 171-195.

Molas-Gallart, J., Salter, A., Patel, P., Scott, A., \& Xavier, D. (2002). Measuring Third Stream Activities, Final Report to the Russell Group of Universities. Sussex: SPRU Science and Technology Policy Research.

Morris, T., \& Wood, S. (1991). Testing the survey method - continuity and change in British industrial-relations. Work Employment and Society, 5(2), 259-282.

Manchester Metropolitan University,. (2009a). HEBCIS - Higher Education Business and Community Interactions Survey. Retrieved 27 November 2009, 2009, from http://www.red.mmu.ac.uk/?pageparent $=3 \&$

Manchester Metropolitan University .,(2009b). Vision of the Future, from http://www.mmu.ac.uk/about/vision/

Robson, C. (1993, 2002). Real World Research (Second Edition ed.). UK: Blackwell Publishing.

Rothaermel, F. T., Agung, S. D., \& Jiang, L. (2007). University entrepreneurship: a taxonomy of the literature. Industrial and Corporate Change, 16(4), 691-791.

Rughase, O. G. (2006). Identity and Strategy: How Individual Visions Enable the Design of a Market Strategy That Works). UK: Edward Elgar Publishing Ltd.

Sainsbury, D. The Race to the Top A Review of Government's Science and Innovation Policies. Retrieved Accessed $15^{\text {th }}$ April 2008, 2008

Saunders, M., Lewis, P., \& Thornhill, A. (1997). Research Methods for Business Students (1 ed.). London: Financial Times Management.

Vanmaanen, J., \& Barley, S. R. (1984). Occupational communities - culture and control in organizations. Research in Organizational Behavior, 6, 287-365.

Wedgwood, M. (2006). Mainstreaming the Third Stream. In I. McNay (Ed.), Beyond Mass Higher Education (pp. 134-157). New York: Open University Press.

Wegge, J., Van Dick, R., Fisher, G. K., Wecking, C., \& Moltzen, K. (2006). Work motivation, organizational identification, and well-being in call centre work. Work and Stress, 20(1), 6083.

Whittington, R. What is Strategy - and does it matter? (2nd Edition ed.): London: Thompson Learning. 